\title{
Age related prefrontal compensatory mechanisms for inhibitory control in the antisaccade task
}

\author{
Juan Fernandez-Ruiz $^{\mathrm{a},{ }^{*}, 1}$, Alicia Peltsch ${ }^{\mathrm{b}, 1}$, Nadia Alahyane ${ }^{\mathrm{b}, \mathrm{f}}$, Donald C. Brien ${ }^{\mathrm{b}}$, Brian C. Coe ${ }^{\mathrm{b}}$, \\ Angeles Garcia $^{\text {b, c }}$, Douglas P. Munoz ${ }^{\text {b, c, d,e }}$

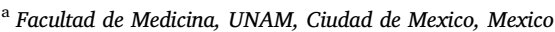 \\ ${ }^{\mathrm{b}}$ Centre for Neuroscience Studies, Queen's University, Kingston, Ontario, Canada

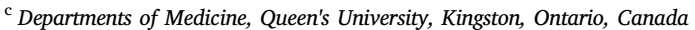 \\ d Biomedical and Molecular Sciences, Queen's University, Kingston, Ontario, Canada \\ ${ }^{\text {e }}$ Psychology, Queen's University, Kingston, Ontario, Canada \\ ${ }^{\mathrm{f}}$ Institut de Psychologie, Universite Paris Descartes, Sorbonne-Paris-Cité, Boulogne-Billancourt, France
}

\section{A R T I C L E I N F O}

\section{Keywords:}

Aging

Cognitive control

fMRI

Saccade

Anterior prefrontal cortex

Frontal pole

\begin{abstract}
A B S T R A C T
Cognitive decline during aging includes impairments in frontal executive functions like reduced inhibitory control. However, decline is not uniform across the population, suggesting individual brain response variability to the aging process. Here we tested the hypothesis, within the oculomotor system, that older adults compensate for agerelated neural alterations by changing neural activation levels of the oculomotor areas, or even by recruiting additional areas to assist with cognitive performance. We established that the observed changes had to be related to better cognitive performance to be considered as compensatory. To probe this hypothesis we used the antisaccade paradigm and analyzed the effect of aging on brain activations during the inhibition of prepotent responses to visual stimuli. While undergoing a fMRI scan with concurrent eye tracking, 25 young adults (21.7 y/ $\mathrm{o} \pm 1.9 \mathrm{SDM})$ and 25 cognitively normal older adults (66.2 y/o $\pm 9.8 \mathrm{SDM})$ performed an interleaved pro/ antisaccade task consisting of a preparatory stage and an execution stage. Compared to young adults, older participants showed a larger increase in antisaccade reaction times, while also generating more antisaccade direction errors. BOLD signal analyses during the preparatory stage, when response inhibition processes are established to prevent an automatic response, showed decreased activations in the anterior cingulate and the supplementary eye fields in the older group. Moreover, older adults also showed additional recruitment of the frontal pole not seen in the younger group, and larger activations in the dorsolateral prefrontal cortex during antisaccade preparation. Additional analyses to address the performance variability in the older group showed distinct behavioral-BOLD signal correlations. Larger activations in the saccade network, including the frontal pole, positively correlated with faster antisaccade reaction times, suggesting a functional recruitment of this area. However, only the activation in the dorsolateral prefrontal cortex during the antisaccade events showed a negative correlation with the number of errors across older adults. These findings support the presence of two dissociable age-related plastic mechanisms that result in different behavioral outcomes. One related to the additional recruitment of neural resources within anterior pole to facilitate modulation of cognitive responses like faster antisaccade reaction times, and another related to increased activation of the dorsolateral prefrontal cortex resulting in a better inhibitory control in aging.
\end{abstract}

\section{Introduction}

There is ample evidence that cognition declines during aging (Salthouse, 2010). This decline, however, is not uniform across the population; some healthy individuals maintain constant cognitive levels across aging, while others show cognitive decay despite being otherwise healthy (Nyberg et al., 2012; Rapp and Amaral, 1992). A range of possibilities could explain this variability, including the preservation of a

\footnotetext{
* Corresponding author. Departamento de Fisiología, Facultad de Medicina, Universidad Nacional Autónoma de México, UNAM, Coyoacán, Ciudad de Mexico 04510, Mexico.

E-mail address: jfr@unam.mx (J. Fernandez-Ruiz).

1 Authors contributed equally to this work.
} 
healthy brain, or the implementation of compensatory mechanisms that could counteract age related brain deterioration (Morcom and Johnson, 2015). Some of the most investigated mechanisms proposed to help maintain the cognitive performance in the elderly emerged from results obtained from imaging studies. These studies have shown significant changes in activation levels in areas known to participate in specific cognitive processes (Cabeza, 2002; Eyler et al., 2011; Reuter-Lorenz and Cappell, 2008). Furthermore, they have even shown the functional recruitment of additional regions not previously associated with the performance of a given cognitive task (Eyler et al., 2011; Reuter-Lorenz and Cappell, 2008). However, more information is needed to establish the specific impact that the observed changes could have on different cognitive processes, including executive functions (Spreng et al., 2010).

A well suited task to analyze the effects of aging on executive functions is the antisaccade task (Guitton et al., 1985; Hallett, 1978). To complete an antisaccade correctly, participants must first inhibit an automatic eye movement towards the presentation of a suddenly appearing peripheral stimulus, and then initiate a voluntary saccade in the opposite direction. Areas involved in this process include the dorsolateral prefrontal cortex (DLPFC) (Guitton et al., 1985; PierrotDeseilligny et al., 1991), the frontal, supplementary and parietal eye fields (FEF, SEF, PEF respectively) (Brown et al., 2007; Connolly et al., 2002; Curtis \& D'Esposito, 2003; DeSouza et al., 2003; Ford et al., 2005), and the basal ganglia (Watanabe and Munoz, 2011). These brain imaging studies have demonstrated that a network of cortical and subcortical structures must be activated prior to the appearance of the visual stimulus so the motor system can then generate the appropriate action, a phenomenon referred to as 'task set' or 'preparatory set' (Munoz and Everling, 2004). The addition of preparatory trials to the antisaccade task allows separate examination of activation related to the preparatory stage including the inhibitory control mechanisms for a pro or an antisaccade, compared to activation related to the execution of the response (Alahyane et al., 2014; Cameron et al., 2012; Witiuk et al., 2014).

Age related deterioration of executive functioning includes deficits in inhibitory control (Eyler et al., 2011), as suggested by previous antisaccade studies showing that inhibitory response performance of elderly participants is considerably more impaired than automatic prosaccade responses (Abel and Douglas, 2007; Abrams et al., 1998; Munoz et al., 1998; Peltsch et al., 2011; Peltsch et al., 2014; Yang and Kapoula, 2006). A number of imaging studies have further demonstrated the effect of aging on the response inhibition in the saccade system (Alichniewicz et al., 2013; Mirsky et al., 2013; Nelles et al., 2009; Pa et al., 2014; Raemaekers, Vink, van den Heuvel, Kahn and Ramsey, 2006). These studies showed that age related activation increases are evident throughout the frontoparietal network during saccade performance in the elderly (Nelles et al., 2009), and particularly during antisaccade trials, suggesting compensatory processes (Raemaekers et al., 2006). However, the possible behavioral correlates of the observed activation changes in the saccade network have not been studied. That is, it is not known if activity-changes including increase, decrease, lateral or antero-posterior activation shifts in saccade related areas, or even the additional recruitment of new areas to the oculomotor circuity, correlate with a better behavioral performance, or if those changes are irrelevant for inhibitory control or saccade execution in the elderly.

Here, our first goal was to test if older adults showed local BOLD activation changes primarily during the preparatory stage of the antisaccade task, when the response inhibition process is established (Alahyane et al., 2014; Munoz and Everling, 2004). Once we obtained the activation differences between the young and the older participants, our second goal was to test the hypothesis that those changes fit mechanisms suggested as compensatory in the elderly. To evaluate this hypothesis we analyzed the areas with age related changes and tested if the changes in activation correlated with the participants' performance, specifically with reaction times and error responses. If those changes showed no correlations, or even correlations with behavioral deficits, that would suggest a maladaptive plastic response. On the contrary, if the changes showed correlations with better behavioral outcomes, it would be suggestive of beneficial aging compensatory mechanisms.

\section{Materials and methods}

All experiments were approved by the Health Sciences and Affiliated Teaching Hospitals Research and Ethics Board of Queen's University and in accordance to the principles of the Canadian Tri-Council Policy Statement (TCPS-2 2014) on Ethical Conduct for Research Involving Humans, and the Declaration of Helsinki (World Medical Association, 2001).

\section{Participants}

Twenty-five healthy young volunteers $(21.7 \mathrm{y} / \mathrm{o} \pm 1.9 \mathrm{SDM}$, age range 18-25 y/o, 14 females) and twenty-five healthy older community dwelling volunteers $(66.2 \mathrm{y} / \mathrm{o} \pm 9.8 \mathrm{SDM}$, age range $49-83 \mathrm{y} / \mathrm{o}, 15 \mathrm{fe}-$ males) participated in a two-hour experiment at the Queen's University magnetic resonance imaging facility (http://neuroscience.queensu.ca/ MRI-facility). All participants had normal or corrected-to-normal vision, or verified that they could distinguish the stimuli without their glasses. Participants reported no neurological or psychiatric illnesses.

\section{Visual display and eye tracking}

Visual stimuli were generated and controlled using E-PRIME software (Psychology Software Tools) on a desktop computer. Images were backprojected onto a high-contrast rear projection screen (DA-LITE), positioned at the head end of the magnet bore, using a NECLT265 DLP video projector with a refresh rate of $60 \mathrm{~Hz}$ and a resolution of $1024 \times 768$. Participants viewed the screen via a mirror attached to the head coil (described below). Eye position data were recorded using an ISCAN ETL400 camera that sampled the eye position at a frequency of $120 \mathrm{~Hz}$. To ensure synchronization, the MRI sequences directly triggered the EPRIME software using a trigger signal from the scanner. An infrared fiberoptic illuminator, which was fixed to the head coil, was used to illuminate the right eye for tracking. After the anatomical MRI scan was acquired, the eye tracker was calibrated using a nine-point array that covered most of the visual field. Analysis of the eye movement data was performed off-line using custom-made MATLAB programs (MathWorks).

\section{Behavioral protocol}

A randomly interleaved, rapid event-related design was used allowing the presentation of different trial types within a short time period. The design included full prosaccade and antisaccade trials aimed at examining both the preparatory and execution components of saccades (Fig. 1, top 2 rows), preparatory-only trials that exclusively measured preparatory activation (Fig. 1, bottom 2 rows), and fixation-only trials (not shown). Participants were asked to fixate on a neutral stimulus (a "gold coin" approximately $2^{\circ}$ of visual angle) that appeared for $1000 \mathrm{~ms}$ at the center of the screen to start each trial. The neutral fixation stimulus would change to an instructional cue indicating that a prosaccade or an antisaccade was required. The instructional cues were colored diagram images of the same size: a green turtle indicated that a prosaccade should be made, while a red crab indicated that an antisaccade was required. Colored diagram symbols were chosen because the rapid event-related experiment was designed for use across various participant groups including children. After the $1300 \mathrm{~ms}$ presentation of the instructional cue, a 200 ms black screen gap period was introduced. This gap has been associated with shorter saccadic reaction times (SRTs), more antisaccade direction errors, and more express prosaccades (Fischer and Weber, 1997; Munoz et al., 1998; Munoz and Corneil, 1995). On saccade trials, a peripheral target (gold coin) was flashed for $100 \mathrm{~ms}$ to the left or right of the neutral fixation, at eccentricities of either $6^{\circ}$ or $7^{\circ}$ in separate trials, to signal a saccade. Participants had $1400 \mathrm{~ms}$ to execute the appropriate 


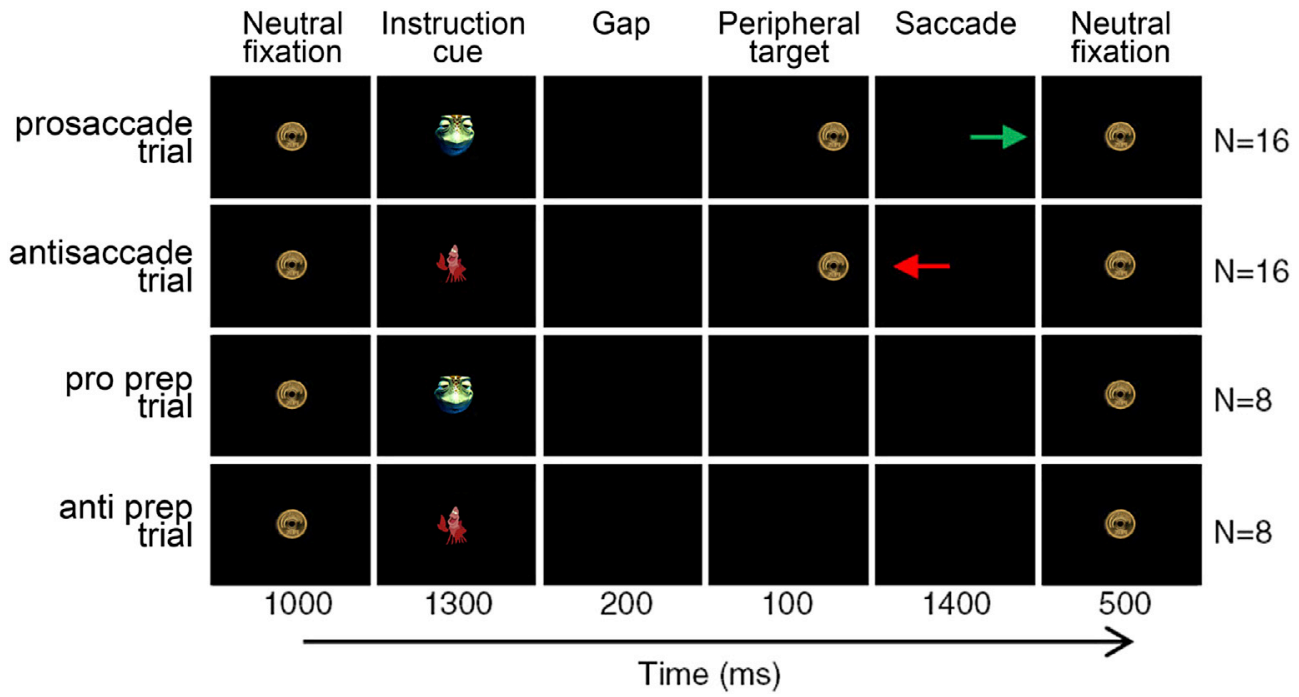

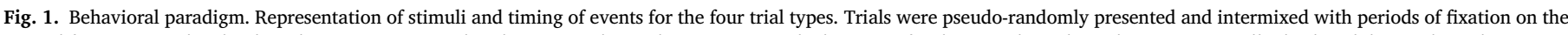

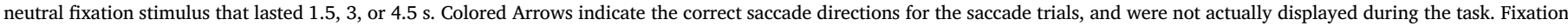
only trials are not show.

prosaccade (look toward the target location) or antisaccade (look away from the target in the opposite direction) based on the instructional cue presented in that trial. Once a trial was finished, the neutral fixation stimulus (gold coin) reappeared at the center of the screen for $500 \mathrm{~ms}$, and participants were required to reestablish central fixation to initiate the next trial. On preparatory trials, the instructional cue was presented and disappeared to initiate the gap period, but the peripheral target never appeared to signal a saccade; subjects were instead required to maintain central fixation for the remainder of the trial $(1700 \mathrm{~ms})$ without generating a saccade. Participants did not know whether or not the peripheral target would appear on any given trial; thus, the instruction cue would always elicit preparation for a prosaccade or antisaccade. Full saccade, preparatory, and fixation only trials were $4500 \mathrm{~ms}$ in duration. The duration of the intertrial interval was jittered, using fixation periods that spanned 1 repetition time (TR) ( $1.5 \mathrm{~s} ; 8$ times), 2 TR ( $3.0 \mathrm{~s} ; 4$ times), and 3 TR (4.5s; 4 times) to increase the statistical efficiency and power in the rapid event-related design (Dale, 1999). Before starting the task, participants were instructed to make a correction saccade if they generated direction errors, e.g. if they looked at the peripheral target in an antisaccade trial. This ensured participants understood the task instructions and could continue in the study.

\section{fMRI experimental design}

Brain imaging was completed according to methodology described previously (Alahyane et al., 2014; Cameron et al., 2012; Hakvoort Schwerdtfeger et al., 2013; Witiuk et al., 2014). All imaging data were acquired using a Siemens 3 T Magnetom Trio system fitted with a 12channel receive-only head coil. High-resolution T1-weighted wholebrain structural scans were performed on each participant using an MPRAGE sequence $\left(\mathrm{TR}=1760 \mathrm{~ms}\right.$, TE $=2.2 \mathrm{~ms}$, flip angle $=9^{\circ}$, $256 \times 256 \mathrm{~mm}$ field of view, and $256 \times 256$ matrix size providing $1 \mathrm{~mm}$ isotropic voxels, 176 slices). Functional data were collected using a T2*weighted EPI acquisition (TR $=1500 \mathrm{~ms}, \mathrm{TE}=30 \mathrm{~ms}$, flip angle $=72^{\circ}$, $211 \times 211 \mathrm{~mm}$ field-of-view, $64 \times 64$ matrix size, $3.3 \mathrm{~mm}$ isotropic voxel resolution, $185 \mathrm{vol}$ ) for BOLD-based imaging (Ogawa et al., 1990). Twenty-four slices were acquired and positioned to include all regions of interest extending from the top of the brain to the ventral striatum (STR).

Runs consisted of 64 trials that included 8 preparatory-pro, 8 preparatory-anti, 16 prosaccade, 16 antisaccade, and 16 fixation trials (Fig. 1; fixation trials not shown). Trial types were pseudo-randomly interleaved, and right and left prosaccade and antisaccade trials were presented in equal quantities within each run. Each participant performed 5-9 runs (depending on eye tracking success and tiredness), with each run lasting $277.5 \mathrm{~s}$. Each run started with an additional fixation period of $3 \mathrm{~s}$, while fMR images were acquired, to allow the MR signal to reach a steady state. Each run ended with a $16.5 \mathrm{~s}$ fixation period to allow the hemodynamic response to return to baseline before starting the next run. Each subject participated in a practice run immediately before entering the magnet.

All functional imaging runs were preprocessed using Brain Voyager QX 2.8.4. The first two volumes of each functional run were discarded before any preprocessing, to allow for steady-state magnetization. To correct for between-scan movements, all volumes within a run were realigned to the first volume of that functional run. Slice scan time correction was conducted to adjust for time differences due to multi-slice imaging acquisition using a cubic spline interpolation, which was based on the TR duration and order of slice scanning (ascending interleaved). 3D spatial smoothing was then performed using a $6 \mathrm{~mm}$ full-width at half-maximum Gaussian filter on all volumes, and each run was filtered to remove linear drift using a high-pass filter with the upper cutoff frequency corresponding to 3 cycles over the length of the run. Finally, all functional data were superimposed onto 3D anatomical images, resampled into $3 \mathrm{~mm}$ cubic voxels, aligned to the anterior commissure-posterior commissure axis, and transformed into Talairach space (Talairach and Tournoux, 1988).

\section{Behavioral analyses}

SRT was defined as the time to make the first saccade away from fixation after peripheral stimulus onset. Saccades with a SRT $<90 \mathrm{~ms}$ were considered anticipatory (Munoz et al., 1998) and thus were excluded from analysis. Prosaccade direction errors were defined as saccades executed away from the peripheral stimulus after prosaccade instruction; whereas antisaccade direction errors were defined as saccades executed toward the peripheral stimulus after antisaccade instruction. Direction error rate was calculated by dividing the total number of errors by the total number of valid trials. Valid trials consisted of all trials except for those that included errors in which participants failed to fixate the instruction, failed to maintain fixation (measured by saccades in any direction during the fixation period), failed to initiate a saccade, or trials in which eye-tracking was unsuccessful. These aforementioned excluded trials represented $8.3 \%$ of the total trials, and were modeled separately as "invalid trials" in the fMRI analysis described 
below. Mixed-design $2 \times 2$ repeated-measures ANOVAs were conducted to examine behavioral differences between the younger and the older group in terms of SRT and percentage of direction errors during antisaccade- and prosaccade trials. Group differences on saccade measures were not observed between leftward versus rightward saccades or between $6^{\circ}$ versus $7^{\circ}$ eccentricities (Paired Student's $t$-test, $\mathrm{p}>0.05$ ); therefore, these responses were pooled.

\section{Imaging analyses}

For the fMRI main contrast analysis, the BOLD time series for each voxel was deconvolved with the canonical hemodynamic response function to estimate the underlying time course of neural activity. The hemodynamic response function was modeled as a 13-point time series with a temporal resolution of $1.54 \mathrm{~s}$. Events were modeled separately in the design matrix according to trial type, including the following: (1) preparatory-anti trials, (2) preparatory-pro trials, (3) correct antisaccade trials, (4) correct prosaccade trials, (5) corrected antisaccade direction errors, and (6) invalid trials. Fixation trials were used as an implicit baseline. Several statistical parametric maps were computed for each group. To identify the saccade related neural network we looked at correct full antisaccade trials and full prosaccade trials over BOLD time points 5-6 (7.7, and $9.3 \mathrm{~s}$ from trial onset), which corresponded to the time intervals of the peak of the BOLD responses from the instructional cue presentation to the saccade execution (illustrated with a gray bar in Fig. 4). These analyses resulted in group-level statistical maps that were generated at a false discovery rate corrected threshold of $\mathrm{p}<0.01(\mathrm{~T}$ value $=5.0$ ). These statistical maps constituted the main contrast, and were used for subsequent ROI second-level analyses pertaining to task set establishment and response execution.

The regions of interest (ROI) for the fMRI analyses were chosen based on previous functional imaging studies that showed consistent activation in these areas during prosaccade and antisaccade execution and preparation (Brown et al., 2006; Cameron et al., 2012; Connolly et al., 2005; DeSouza et al., 2003; Ford et al., 2006; Hakvoort Schwerdtfeger et al., 2013; Jamadar et al., 2013; Luna et al., 1998; Raemaekers et al., 2006; Witiuk et al., 2014). The following ROIs were selected from the main contrast to perform second level analyses and are known to participate in the saccade network: the frontal pole (FP), DLPFC, the insula (INS), the anterior cingulate cortex (ACC), the STR, the SEFs, the FEF, the precuneus ( $\mathrm{PCu}$ ), and the parietal eye fields (PEFs). ROI analyses were conducted using random-effects Gaussian linear models to extract $\beta$-weight parameter estimates of BOLD signal change during saccades from each ROI. ROIs were identified using anatomical landmarks and known locations in Talairach space. Each ROI was defined as the 125 contiguous voxels $(5 \times 5 \times 5)$ within a cubic cluster centered on the point of local maxima activation within the selected region. Peak preparatory activation was measured as the mean $\beta$-weight values from the fifth and sixth time points following preparatory trial onset (Fig. 4 shaded bar). For analysis of the saccade execution processes, the time points were shifted by $1.5 \mathrm{~s}$ to include the sixth and seventh time points following saccade trial onset, as the presentation of the peripheral target occurs $1.5 \mathrm{~s}$ (one time point) after the appearance of the instruction (Alahyane et al., 2014; Brown et al., 2007). Mixed-design Split-Plot ANOVAs with one within-subjects factor (with two levels: pro and anti) and one between-subjects factor (with two levels: younger group and older group) were then conducted to examine differences in mean $\beta$-weight values for all ROIs using IBM SPSS Statistics for Windows, version 23 (IBM Corp., Armonk, N.Y., USA), obtaining F-statistic, $p$ and Eta-squared $\left(\eta_{\mathrm{p}}^{2}\right)$ values. Paired Student's t tests were conducted to analyze the interhemispheric differences during the preparatory activity following an antisaccade cue for both groups using the $\beta$-weight averages of the fifth and sixth time points. Finally, to evaluate the relationship between BOLD signal change and task performance, Pearson's correlations were performed between $\beta$-weight values and behavioral measurements, including SRT and percentage of direction errors.

\section{Results}

\section{Behavioral results}

A summary of the behavioral results is provided in Fig. 2. Analysis of SRT showed significant prolonged antisaccade latencies compared to prosaccades in both groups $\left(\mathrm{F}(1,48)=23.46, \mathrm{p}<0.01, \eta_{\mathrm{p}}^{2}=0.32\right)$. Although there was no main effect of group $(F(1,48)=1.67, p=0.38$, $\eta_{\mathrm{p}}^{2}=0.03$ ), there was a larger antisaccade reaction time increase in the elderly group compared to the younger group $(\mathrm{F}(1,48)=4.06, \mathrm{p}=0.04$, $\eta_{\mathrm{p}}^{2}=0.07$ ) (Fig. 2A).

Analysis of saccade direction errors showed a significant larger number of direction errors in the antisaccade than the prosaccade condition $\left(\mathrm{F}(1,48)=17.18, \mathrm{p}<0.01, \eta_{\mathrm{p}}^{2}=0.26\right)$. The analysis also showed a significant larger number of errors in the older group $(F(1,48)=14.63$, $p$ $=<0.01, \eta_{\mathrm{p}}^{2}=0.23$ ), and a significant group by condition effect that resulted from a larger increase in the number of antisaccade errors in the elderly group $\left(\mathrm{F}(1,48)=7.63, \mathrm{p}=0.01, \eta_{\mathrm{p}}^{2}=0.13\right)$ (Fig. $2 \mathrm{~B}$ ).

\section{fMRI results}

\section{The saccade network}

The initial main contrast analysis (see Methods), found regions involved in the preparation and execution of pro and anti-saccades. This analysis identified the characteristic oculomotor network previously reported in other imaging studies (Alahyane et al., 2014; Anderson et al., 2012; Brown et al., 2006, 2007; Connolly et al., 2005; Ford et al., 2006; Jamadar et al., 2013; Luna et al., 1998). Our results included the FP, DLPFC, INS, ACC, SEF, FEF, STR, PCu, and PEF. Fig. 3 depicts relevant slices for the oculomotor network for the young and older groups, and Table 1 lists the Talairach locations of peak activation for all key ROIs. As expected, both groups recruited almost all predefined ROIs, with the exception of FP, which only showed activation in the older group. The ROIs obtained from this analysis were then selected for second-level analyses to dissect the differential contribution to preparatory and execution processes.

\section{Preparatory activity in the saccade network}

Once the saccade network ROIs were defined, we plotted the BOLD signal time courses corresponding to the pro and anti-preparatory trials (Fig. 4). To determine the effect of aging on the processes specifically involved in the preparation of the oculomotor network to an impending prosaccade or antisaccade (Alahyane et al., 2014), we analyzed the peak BOLD responses from the instructional cue presentation from the preparatory-pro and preparatory-anti trials (Fig. 5). Group comparisons of the $\beta$ weight values from the saccade network ROIs are shown in Fig. 5.

The analysis to evaluate if there were activation differences between the younger and older groups during the preparatory pro and anti trials yielded significant group differences in three ROIs, including ACC $\left(\mathrm{F}(1,48)=3.98, \mathrm{p}=0.05, \eta_{\mathrm{p}}^{2}=0.07\right), \operatorname{SEF}(\mathrm{F}(1,48)=5.84, \mathrm{p}=0.02$, $\left.\eta_{\mathrm{p}}^{2}=0.1\right)$, and FP $\left(\mathrm{F}(1,48)=12.99, \mathrm{p}<0.01, \eta_{\mathrm{p}}^{2}=0.21\right)$. It should be noted, however, that the differences in ACC and SEF were driven by higher BOLD activations in the younger group, while the difference in FP was the result of larger activity in the older group (Fig. 5). No other ROIs showed significant group differences (Table 2).

We were especially interested in analyzing whether older participants responded differently than the younger participants when they had to inhibit the automatic response versus simply producing the automatic response (i.e., the age by condition interaction). This analysis on the preparatory pro and anti trials showed a significant activity increase only in the older group DLPFC during preparatory-anti trials compared to the younger group. That is, when preparing a response to the prosaccade or antisaccade visual cues, the group (younger and older) by condition (prosaccade and antisaccade) interaction was significant only for DLPFC $\left(\mathrm{F}(1,48)=8.21, \mathrm{p}<0.01, \eta_{\mathrm{p}}^{2}=0.14\right)$ (Fig. 5). 

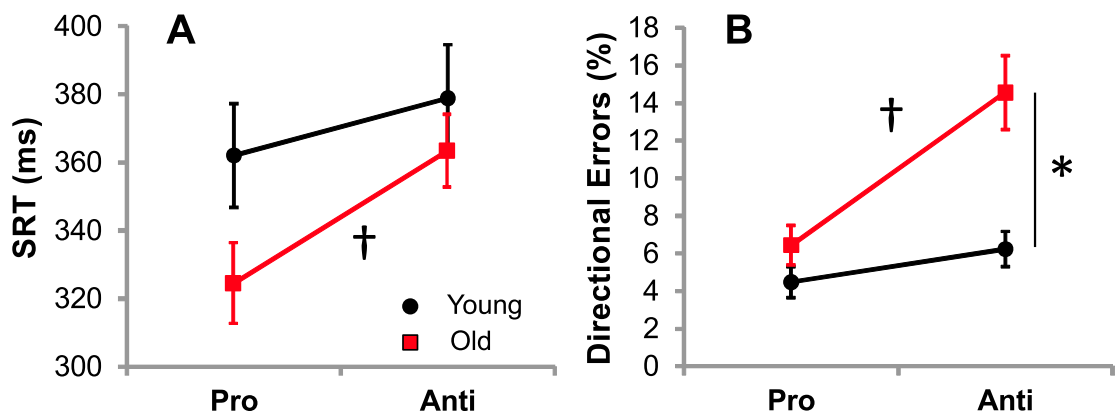

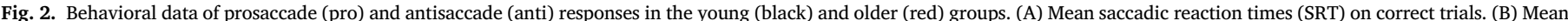
percentage of directional antisaccade errors. Error bars represent standard error of the mean (SE); $\dagger=$ group by task interactions at $\mathrm{p}<0.05, *=$ group main effect at $\mathrm{p}<0.05$.

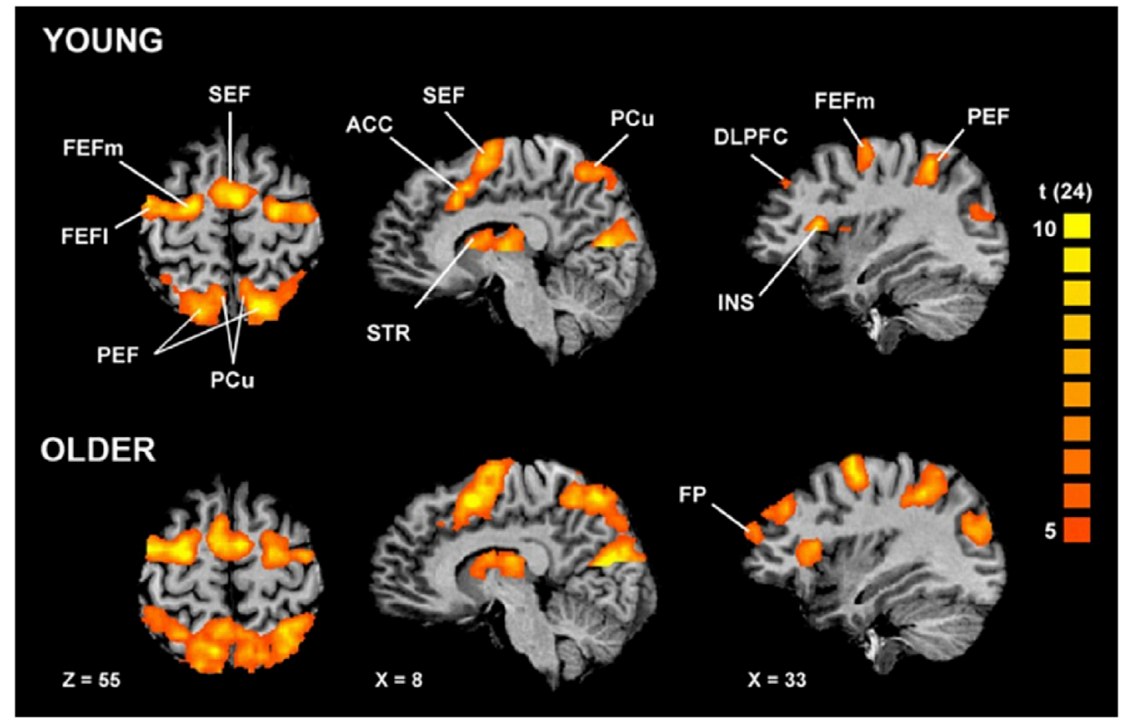

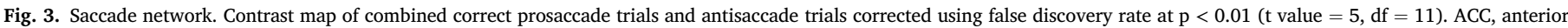

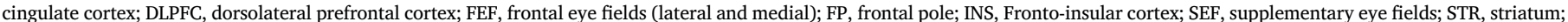
$\mathrm{PCu}$, precuneus; PEF, parietal eye fields.

Table 1

Regions of Interest. Talairach coordinates (X,Y,Z) of cubic clusters containing the 125 most significant voxels centered around peak activation in ROIs derived from the antisaccade + prosaccade contrast maps (Fig. 3). Symbols and definitions: $\mathrm{CH}$, cerebral hemisphere, FP, frontal pole; DLPFC, dorsolateral prefrontal cortex; INS, insular cortex; ACC, anterior cingular cortex; STR, striatum, SEF, supplementary eye fields; FEF, frontal eye fields; PCu, precuneus; PEF, parietal eye fields. All ROIs were taken at local maxima.

\begin{tabular}{|c|c|c|c|c|c|c|c|c|c|}
\hline \multirow[t]{2}{*}{ ROI } & \multirow[t]{2}{*}{$\mathrm{CH}$} & \multicolumn{4}{|c|}{ Young } & \multicolumn{4}{|l|}{ Old } \\
\hline & & $\mathrm{X}$ & $\mathrm{Y}$ & $\mathrm{Z}$ & $\mathrm{T}$ value & $\mathrm{X}$ & $\mathrm{Y}$ & $\mathrm{Z}$ & $\mathrm{T}$ value \\
\hline \multirow[t]{2}{*}{ FP } & $\mathrm{L}$ & -29 & 44 & 9 & 2.03 & -33 & 52 & 22 & 5.74 \\
\hline & $\mathrm{R}$ & 29 & 46 & 11 & 3.04 & 33 & 54 & 20 & 6.58 \\
\hline \multirow[t]{2}{*}{ DLPFC } & $\mathrm{L}$ & -36 & 37 & 34 & 7.88 & -36 & 32 & 37 & 5.29 \\
\hline & $\mathrm{R}$ & 33 & 35 & 37 & 7.04 & 36 & 37 & 34 & 8.3 \\
\hline \multirow[t]{2}{*}{ INS } & $\mathrm{L}$ & -28 & 17 & 11 & 11.35 & -32 & 22 & 6 & 7.17 \\
\hline & $\mathrm{R}$ & 35 & 18 & 11 & 8.96 & 36 & 19 & 8 & 7.83 \\
\hline \multirow[t]{2}{*}{ ACC } & $\mathrm{L}$ & -3 & 0 & 52 & 13.89 & -7 & -3 & 55 & 13.44 \\
\hline & $\mathrm{R}$ & 7 & 11 & 42 & 9.34 & 7 & 8 & 50 & 17.43 \\
\hline \multirow[t]{2}{*}{ STR } & $\mathrm{L}$ & -21 & 0 & 12 & 14.45 & -23 & 1 & 13 & 9.92 \\
\hline & $\mathrm{R}$ & 22 & 0 & 10 & 13.45 & 21 & 2 & 9 & 12.73 \\
\hline \multirow[t]{2}{*}{ SEF } & $\mathrm{L}$ & -7 & -9 & 69 & 11.23 & -15 & -7 & 68 & 8.44 \\
\hline & $\mathrm{R}$ & 2 & -4 & 66 & 10.99 & 7 & -9 & 67 & 8.21 \\
\hline \multirow[t]{2}{*}{ FEF } & $\mathrm{L}$ & -27 & -9 & 60 & 12.07 & -30 & -2 & 59 & 8.31 \\
\hline & $\mathrm{R}$ & 22 & -6 & 59 & 10.31 & 30 & -4 & 58 & 12.14 \\
\hline \multirow[t]{2}{*}{ Pcu } & $\mathrm{L}$ & -15 & -66 & 56 & 12.32 & -18 & -68 & 47 & 10.82 \\
\hline & $\mathrm{R}$ & 15 & -68 & 52 & 10.15 & 10 & -66 & 52 & 12.51 \\
\hline \multirow[t]{2}{*}{ PEF } & $\mathrm{L}$ & -40 & -47 & 45 & 8.89 & -41 & -46 & 49 & 9.75 \\
\hline & $\mathrm{R}$ & 33 & -48 & 45 & 9.4 & 33 & -47 & 47 & 9.29 \\
\hline
\end{tabular}

Correlations between age-related activation changes and behavioral performance

To analyze the nature of the changes observed in the older group during the preparatory stage, we performed additional correlation analyses between individual ROIs preparatory activity and the reaction time (RT) scores during antisaccades. These analyses showed significant negative correlations in core structures involved in saccade preparation, including FEF $(r=-0.4, p=0.04)$, SEF $(r=-0.56, p<0.01)$, ACC $(\mathrm{r}=-0.42, \mathrm{p}=0.03)$, STR $(\mathrm{r}=-0.55, \mathrm{p}<0.01)$, PCu $(\mathrm{r}=-0.49$, $\mathrm{p}=0.01)$ and $\operatorname{PEF}(\mathrm{r}=-0.48, \mathrm{p}=0.01)$ (Fig. 6). Furthermore, there were also significant negative correlations between the reaction time and the preparatory activity in DLPFC $(r=-0.61, \mathrm{p}<0.01)$ and FP $(\mathrm{r}=-0.52$, $\mathrm{p}<0.01$ ), suggesting that larger activations during the preparatory phase in these areas led to faster antisaccade reaction times (Fig. 6).

We then analyzed if the activation levels of these ROIs correlated with the percent of direction antisaccade errors made by the older participants. That is, we explored if subjects with larger activations in these ROIs showed less errors than those with smaller activations. The analyses revealed that the only significant correlation was in the DLPFC ( $\mathrm{r}=-0.61, \mathrm{p}<0.01$ ) (local maxima at $\mathrm{X}=36, \mathrm{Y}=32, \mathrm{Z}=37$, Talairach coordinates) (Fig. 7), suggesting that larger DLPFC activations during the preparatory period led to a smaller proportion of antisaccade errors.

\section{Interhemispheric differences}

One of the most influential models regarding age related changes in the brain suggests that there is a hemispheric asymmetry reduction in the 


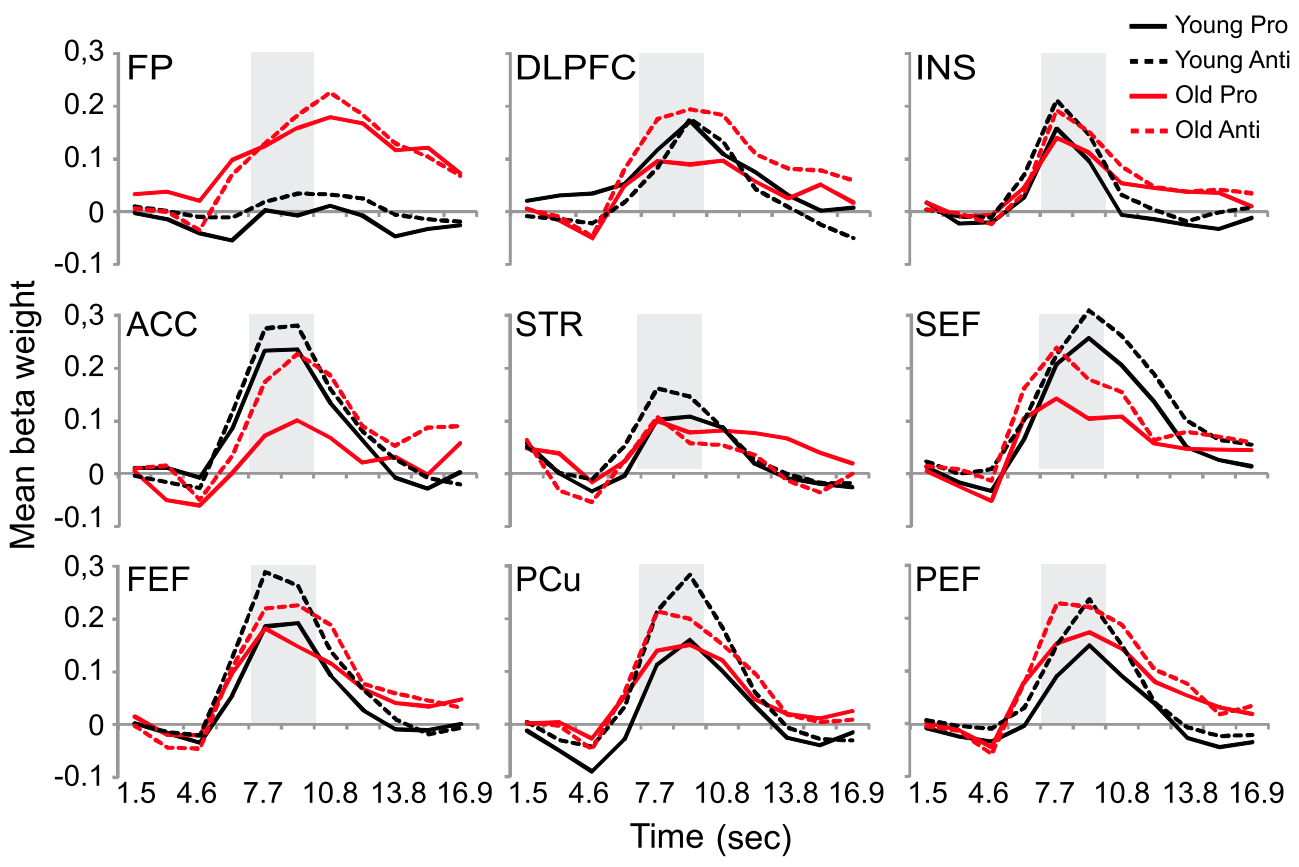

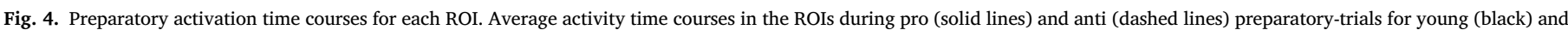
older (red) participants. Gray bars represent the time points used for subsequent analysis.

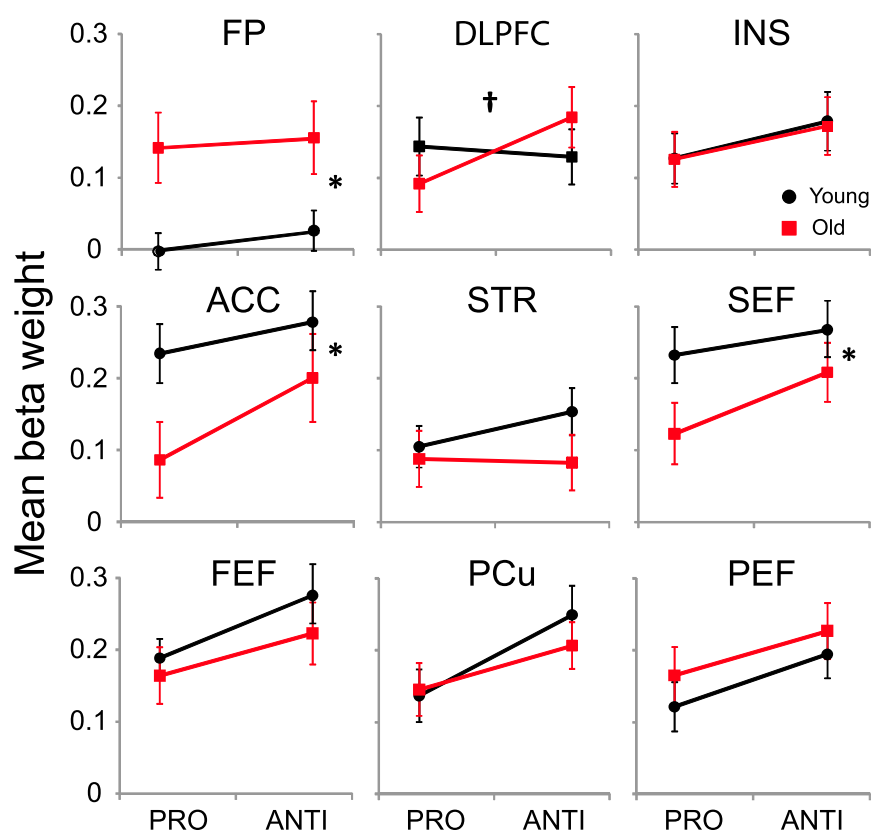

Fig. 5. Preparatory pro and anti trials analyses for each ROI. Group by condition interaction analyses using the mean $\beta$ weight peak activity during preparatory pro and anti trials for young (black) and older (red) groups. * represent between group differences at $\mathrm{p}<0.05 ; \dagger$ denotes a significant group by condition interaction at $\mathrm{p}<0.05$.

activity in old participants (HAROLD) when doing cognitive tasks like episodic memory retrieval (Cabeza, 2002). To evaluate possible shifts in hemispheric activity dominance as suggested by the HAROLD hypothesis, we compared the differences in the mean peak $\beta$ weights of each region across hemispheres using paired-samples t-tests. The results showed only one interhemispheric difference in the young group, having the left ACC a larger activation than the right ACC $(t(24)=7.4, p<0.01)$. All the other comparisons were not significant (Table 3). The interhemispheric differences analyses in the older group did not show significant difference in any ROI, including ACC (Table 3).
Table 2

Preparatory activity. Young and older adults group comparisons results from the ROIs Mixed-design ANOVAs. Abbreviations same as Table 1. Note that bold characters denote statistically significant values.

\begin{tabular}{llll}
\hline ROI & $\mathrm{F}_{(1,48)}$ value & P value & $\eta_{\mathrm{p}}^{2}$ value \\
\hline ACC & 3.98 & $\mathbf{0 . 0 5}$ & 0.07 \\
DLPFC & 0.003 & 0.95 & 0 \\
FEF & 1.12 & 0.29 & 0.02 \\
FP & 12.99 & $\mathbf{0 . 0 1}$ & 0.21 \\
INS & 0 & 0.98 & 0 \\
PCu & 0.16 & 0.68 & 0 \\
PEF & 1.1 & 0.29 & 0.02 \\
SEF & 5.84 & $\mathbf{0 . 0 2}$ & 0.1 \\
STR & 1.92 & 0.17 & 0.03 \\
\hline
\end{tabular}

The saccade execution network

The main focus of our analysis was on the preparatory activity recorded from the preparatory trials to avoid the overlap of the hemodynamic responses related to the processes involved in task set preparation, from those related to the stimulus appearance and saccade execution. However, we also analyzed the activity during the execution trials to try to better understand the effect of aging on these processes. To isolate ROI activation involved in the execution of a prosaccade or antisaccade, we analyzed the mean peak $\beta$ weights of each region using the sixth and seventh time points ( 9.3 and $10.8 \mathrm{~s}$ from trial onset) of prosaccade and antisaccade trials minus the preparatory activation from preparatory trials reported above (Alahyane et al., 2014). There were significant larger activations in the older group in STR $(\mathrm{F}(1,48)=4.08$, $\left.\mathrm{p}=0.04, \eta_{\mathrm{p}}^{2}=0.07\right)$ and DLPFC $\left(\mathrm{F}(1,48)=4.93, \mathrm{p}=0.03, \eta_{\mathrm{p}}^{2}=0.09\right)$, and a large trend in $\mathrm{FP}\left(\mathrm{F}(1,48)=3.81, \mathrm{p}=0.057, \eta_{\mathrm{p}}^{2}=0.07\right)$. The other ROIs did not show statistical differences (Table 4, left). The analysis of the group by conditions interactions only were significant for DLPFC $\left(\mathrm{F}(1,48)=4.93, \mathrm{p}=0.03, \eta_{\mathrm{p}}^{2}=0.09\right)$ and $\mathrm{FEF}(\mathrm{F}(1,48)=4.69, \mathrm{p}=0.49$, $\left.\eta_{\mathrm{p}}^{2}=0.07\right)$, in both cases due to activation reductions in the older group during the antisaccade execution compared to the prosaccade condition. All the other ROIs did not show significant group by condition interactions (Table 4, right). 


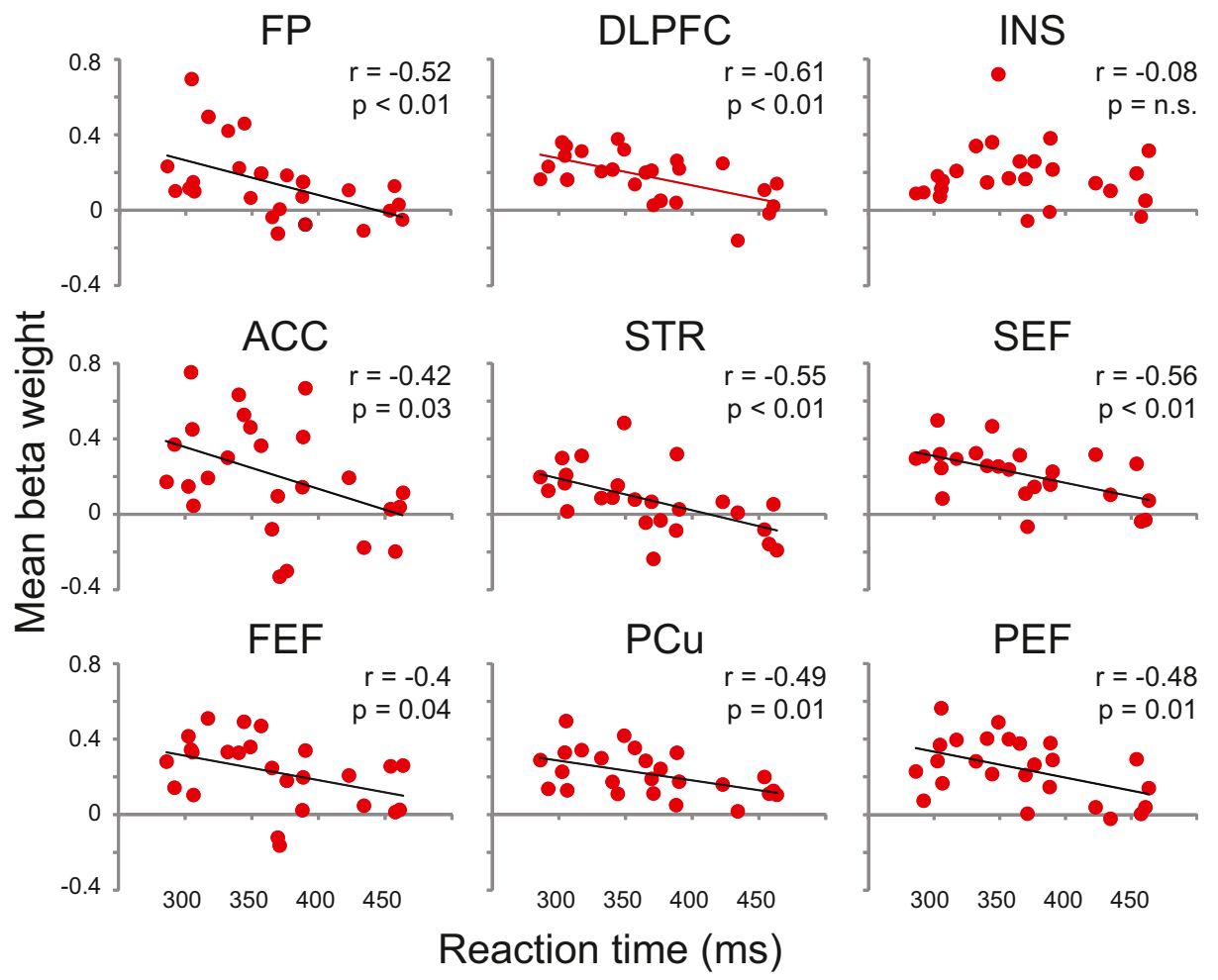

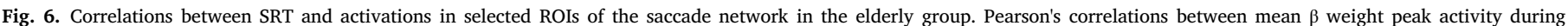

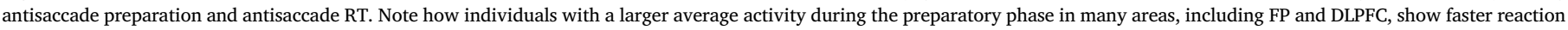
times when executing correct antisaccades.

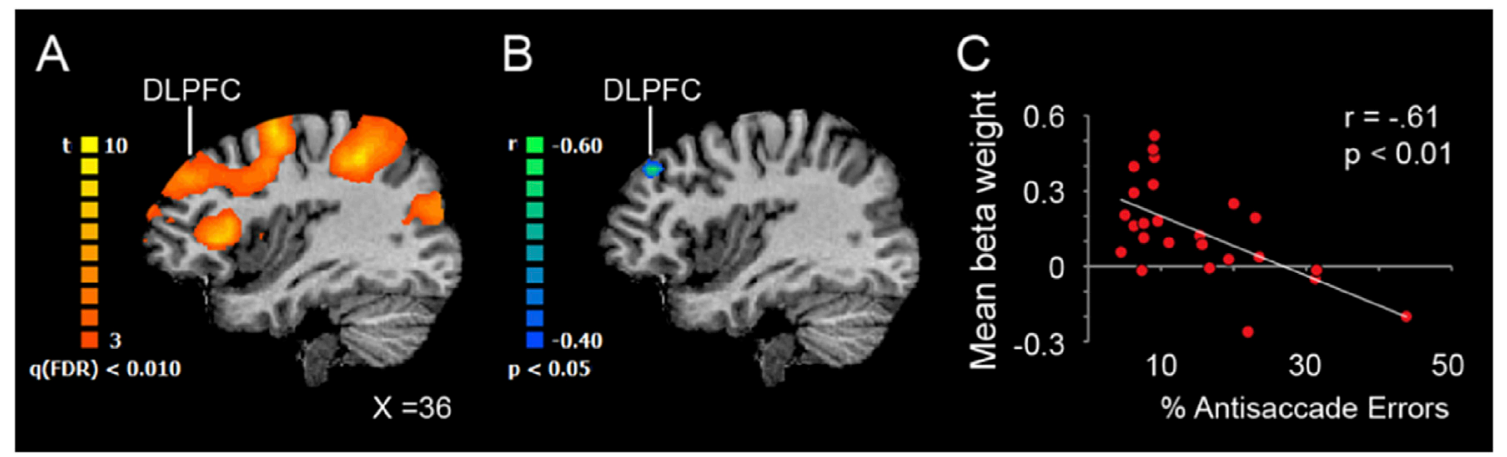

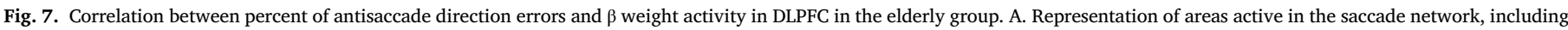

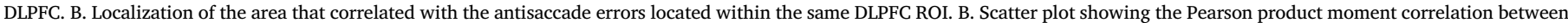
antisaccade directional errors and the elderly participants $\beta$ weight activity in the same DLPFC ROI.

Table 3

Analysis of interhemispheric activations in the saccade network ROIs in the younger and older groups. Note that bold characters denote statistically significant values.

\begin{tabular}{llllll}
\hline \multirow{2}{*}{ ROI } & \multicolumn{2}{l}{ Younger } & & \multicolumn{2}{l}{ Older } \\
\cline { 2 - 3 } \cline { 5 - 6 } & $\mathrm{t}_{(24)}$ & $\mathrm{P}$ & & $\mathrm{t}_{(24)}$ & $\mathrm{P}$ \\
\hline ACC & 7.4 & $\mathbf{0 . 0 1}$ & & 0.32 & 0.75 \\
DLPFC & 1.29 & 0.2 & & -1.68 & 0.1 \\
FEF & 1.32 & 0.19 & & -0.86 & 0.39 \\
FP & -1.11 & 0.27 & & -1.26 & 0.21 \\
INS & 1.82 & 0.08 & & -0.16 & 0.87 \\
PCu. & 61 & 0.54 & & -1.86 & 0.07 \\
PEF & 1.97 & 0.06 & & 0.19 & 0.85 \\
SEF & -0.26 & 0.58 & & -1.3 & 0.2 \\
STR & 43 & 0.67 & -0.22 & 0.82 \\
\hline
\end{tabular}

Table 4

BOLD activation contrast between younger and older groups during pro and anti-saccade trials (left), and group by condition interaction during pro and anti saccade trials (right). Note that bold characters denote statistically significant values.

\begin{tabular}{|c|c|c|c|c|c|c|}
\hline \multirow[t]{2}{*}{ ROI } & \multicolumn{3}{|c|}{ Group Effect } & \multicolumn{3}{|c|}{ Group x Condition Effect } \\
\hline & $F_{(1,48)}$ & $\mathrm{P}$ & $\eta \mathrm{p} 2$ & $F_{(1,48)}$ & $\mathrm{P}$ & $\eta \mathrm{p} 2$ \\
\hline ACC & 1.85 & 0.18 & 0.03 & 0.47 & 0.49 & 0.01 \\
\hline DLPFC & 4.93 & 0.03 & 0.09 & 4.93 & 0.03 & 0.09 \\
\hline FEF & 0.62 & 0.43 & 0.01 & 4.69 & 0.49 & 0.07 \\
\hline FP & 3.81 & 0.05 & 0.07 & 1.12 & 0.27 & 0.02 \\
\hline INS & 3.06 & 0.08 & 0.06 & 0 & 0.93 & 0 \\
\hline $\mathrm{PCu}$ & 2.01 & 0.16 & 0.04 & 0 & 0.95 & 0 \\
\hline PEF & 2.62 & 0.11 & 0.05 & 0.03 & 0.86 & 0 \\
\hline SEF & 1.7 & 0.19 & 0.03 & 1.05 & 0.31 & 0.02 \\
\hline STR & 4.08 & 0.04 & 0.07 & 0.46 & 0.49 & 0.01 \\
\hline
\end{tabular}




\section{Discussion}

We evaluated brain activation differences between young and older participants while they performed an antisaccade task that relies on inhibitory control of oculomotor responses to impending stimuli. We initially tested if there were BOLD signal activation differences between the young and the older group. Our analyses clearly showed significant group differences in the preparatory stage of the antisaccade task, when subjects implemented the inhibitory processes required to prevent an automatic saccade to an impending stimulus (Munoz and Everling, 2004). Based on these analyses we then explored how our results fitted into current competing hypotheses that have been proposed as compensatory mechanisms in the elderly, including activation changes in the network components or even the recruitment of novel areas. Our results found that older participants showed a larger antisaccade RT increase that had a significant negative correlation with BOLD activity across the saccade oculomotor system. Older participants also showed an emerging activation in the frontal pole not seen in the younger group. This FP activation was also negatively correlated with antisaccade RT. Regarding age related changes in response inhibition performance, the older group made more antisaccade directional errors. The analysis of the possible neural basis of this deterioration showed that only the DLPFC activation was negatively correlated with the number of antisaccade direction errors, suggesting that among the elderly, those participants with smaller increases in activity in this area produced more errors.

\section{Antisaccade changes in aging}

Our results were consistent with previous studies showing response inhibition deficits (Rabbitt, 1965), and antisaccade impairments in the elderly (Abel and Douglas, 2007; Abrams et al., 1998; Munoz et al., 1998; Peltsch et al., 2011, 2014; Yang and Kapoula, 2006). Here we specifically explored changes in antisaccade RT and directional errors. Although the analysis did not identify group differences in RT, they did show a significant RT increase during the antisaccade trials in the older group, supporting previous studies showing RT increases in healthy aging (Olincy et al., 1997). The analyses of BOLD activation in the traditional saccade network showed significant activation reductions in the older group in ACC and SEF. Both areas have been critically involved in the production of antisaccades (Amador et al., 2004; Johnston et al., 2007; Polli et al., 2005), suggesting that a decrease in activity could compromise antisaccade performance in the older group. Supporting this idea, the correlational analyses showed that those subjects that could not maintain high levels of activation in these structures during the preparatory period had longer reaction times during the antisaccade trials. These activation reductions, however, were accompanied by significant activity recruitment in the FP. This area, also known as anterior prefrontal cortex, including Brodmann area 10, has been associated with high-level cognitive processes, such as mediating the ability to hold goals in mind while exploring and processing a secondary goal (Koechlin et al., 1999). Our results showed not only a significant recruitment of this area during the antisaccade preparation period in elderly, but the analysis also showed a significant correlation with antisaccade RT: larger activations were correlated to the shortest RT. These results suggest a functional integration of FP within the saccade system in the elderly, which presumably could be considered as a compensatory mechanism as discussed in the next section. Other areas involved in the saccade system showing correlations with the RT included ACC, SEF, FEF, STR, PCu, PEF and DLPFC.

We also observed more directional antisaccade errors in the older group, which has also been previously documented (Butler and Zacks, 2006; Olincy et al., 1997; Munoz et al., 1998; Peltsch et al., 2011). The analysis of the ROIs showed that only the DLPFC had a significant correlation between the preparatory activation levels and the percentage of antisaccade errors. Previous studies have shown that transient inactivation (Nyffeler et al., 2007), or permanent lesions (Guitton et al., 1985;
Pierrot-Deseilligny et al., 2003) of the DLPFC result in a significant increase of antisaccade errors in humans. Further imaging studies have also shown selective activation of the DLPFC during planning of antisaccades and its disruption during antisaccade errors (Ford et al., 2005; McDowell et al., 2002; Witiuk et al., 2014).

\section{Relation to current aging compensatory hypotheses}

A number of theories have been proposed to explain brain changes observed during aging, but the most consistent findings are related to dedifferentiation or reduced activations, including reductions in hemispheric asymmetries (HAROLD), posterior-anterior shifts in activity, and the recruitment of novel areas during performance of specific tasks (Cabeza et al., 2002; Davis et al., 2008; Park and Reuter-Lorenz, 2009; Schneider-Garces et al., 2010). Our results allowed us to analyze how our findings compared to previous results regarding these possible changes. First, in relation to hemispheric asymmetry, our results in the younger group showed an asymmetry only in ACC. This asymmetry was not significant in the older group, a finding that could indicate support for the HAROLD hypothesis - at least in one region involved in the oculomotor circuitry (Cabeza, 2002). However, it should be noted that ACC activity was significantly reduced in the older group, so this could be interpreted not as a compensatory mechanism, but instead as an age-related attenuation of activity levels in both ACCs. Regarding the posterior-anterior shifts in activity, our results did not show any decrease in activity in the posterior ROIs of the saccade network, and therefore the posterior-anterior shift hypothesis was not supported in this study. Our results did, however, show a significant increase of activity in the DLPFC that correlated with better performance in the antisaccade task, thereby supporting the activation compensatory mechanism theory (Cappell et al., 2010; Reuter-Lorenz and Cappell, 2008). Finally, regarding the neural recruitment of novel areas, our results show a significant prefrontal recruitment outside the traditional oculomotor system that correlates with behavioral performance. There is ample evidence of over-recruitment in older adults in other cognitive domains, like memory (Cabeza et al., 2002), including the novel recruitment of medial temporal and dorsolateral prefrontal cortices to support visual memory (McIntosh et al., 1999); these findings have also been supported by a meta-analyses suggesting that frontal over-recruitment in old adults seems more extensive in executive tasks (Spreng et al., 2010). Our results clearly support the novel recruitment of the FP, which is an area that does not participate in the generation of antisaccades in our younger group, or according to the previously reported antisaccade literature.

In conclusion, our findings revealed significant age-related changes in inhibitory control by quantifying increased reaction times and error rates in an antisaccade task. These changes were accompanied with the recruitment of an additional prefrontal area, the bilateral FP, not normally involved in the oculomotor saccadic system. This area showed a similar activation pattern as the other areas regularly involved in the establishment of the antisaccade task set implemented for the inhibition of automatic responses, suggesting a smooth functional integration. Our results also confirm the critical role of the DLPFC in the correct generation of antisaccades. The significant increase of DLPFC activity specifically during the preparatory stage of antisaccade trials in the older group could be interpreted as a compensatory mechanism, since it is associated with better performance. Finally, further research is needed to analyze the functional role of the additional neural recruitment observed in the FP. For instance, studies could aim to induce functional inactivation of this area using known techniques like transcranial magnetic stimulation as has been demonstrated for episodic memory (Rossi et al., 2004).

\section{Funding}

This work was supported by Canadian Institutes of Health Research Operating Grant FDN 148418 to D.P.M. who was also supported by the Canada Research Chair Program 950-230425. 


\section{Acknowledgements}

We are grateful to the volunteers that participated in this study.

\section{References}

Abel, L.A., Douglas, J., 2007. Effects of age on latency and error generation in internally mediated saccades. Neurobiol. Aging 28 (4), 627-637. http://doi.org/10.1016/j. neurobiolaging.2006.02.003.

Abrams, R.A., Pratt, J., Chasteen, A.L., 1998. Aging and movement: variability of force pulses for saccadic eye movements. Psychol. Aging 13 (3), 387-395. https://doi.org/ 10.1037/0882-7974.13.3.387.

Alahyane, N., Brien, D.C., Coe, B.C., Stroman, P.W., Munoz, D.P., 2014. Developmenta improvements in voluntary control of behavior: effect of preparation in the frontoparietal network? NeuroImage 98, 103-117. http://doi.org/10.1016/j.neuroimage. 2014.03.008.

Alichniewicz, K.K., Brunner, F., Klünemann, H.H., Greenlee, M.W., 2013. Neural correlates of saccadic inhibition in healthy elderly and patients with amnestic mild cognitive impairment. Front. Psychol. 4, 1-12. JUL. http://doi.org/10.3389/fpsyg. 2013.00467.

Amador, N., Schlag-Rey, M., Schlag, J., 2004. Primate antisaccade. II. Supplementary eye field neuronal activity predicts correct performance. J. Neurophysiol. 91 (4), 1672-1689. http://doi.org/10.1152/jn.00138.2003.

Anderson, E.J., Jones, D.K., O'Gorman, R.L., Leemans, A., Catani, M., Husain, M., 2012 Cortical network for gaze control in humans revealed using multimodal MRI. Cereb. Cortex 22 (4), 765-775. New York, N.Y.: 1991. http://doi.org/10.1093/cercor/ bhr110.

Brown, M.R.G.G., Goltz, H.C., Vilis, T., Ford, K.A., Everling, S., 2006. Inhibition and generation of saccades: rapid event-related fMRI of prosaccades, antisaccades, and nogo trials. NeuroImage 33 (2), 644-659. http://doi.org/10.1016/j.neuroimage. 2006.07.002.

Brown, M.R.G., Vilis, T., Everling, S., 2007. Frontoparietal activation with preparation for antisaccades. J. Neurophysiol. 98 (3), 1751-1762. http://doi.org/10.1152/jn.00460. 2007.

Butler, K.M., Zacks, R.T., 2006. Age deficits in the control of prepotent responses: evidence for an inhibitory decline. Psychol. Aging 21 (3), 638-643. http://doi.org/ 10.1037/0882-7974.21.3.638.

Cabeza, R., 2002. Hemispheric asymmetry reduction in older adults: the HAROLD model. Psychol. Aging 17 (1), 85-100. http://doi.org/10.1037/0882-7974.17.1.85.

Cabeza, R., Anderson, N.D., Locantore, J.K., McIntosh, A.R., 2002. Aging gracefully: compensatory brain activity in high-performing older adults. NeuroImage 17 (3), 1394-1402. http://doi.org/10.1006/nimg.2002.1280.

Cameron, I.G.M., Pari, G., Alahyane, N., Brien, D.C., Coe, B.C., Stroman, P.W., Munoz, D.P., 2012. Impaired executive function signals in motor brain regions in Parkinson's disease. NeuroImage 60 (2), 1156-1170. http://doi.org/10.1016/j. neuroimage.2012.01.057.

Cappell, K.A., Gmeindl, L., Reuter-Lorenz, P.A., 2010. Age differences in prefontal recruitment during verbal working memory maintenance depend on memory load. Cortex 46 (4), 462-473. http://doi.org/10.1016/j.cortex.2009.11.009.

Connolly, J.D., Goodale, M. a, Menon, R.S., Munoz, D.P., 2002. Human fMRI evidence for the neural correlates of preparatory set. Nat. Neurosci. 5 (12), 1345-1352. http:// doi.org/10.1038/nn969.

Connolly, J.D., Goodale, M.A., Goltz, H.C., Munoz, D.P., 2005. fMRI activation in the human frontal eye field is correlated with saccadic reaction time. J. Neurophysiol. 94 (1), 605-611. http://doi.org/10.1152/jn.00830.2004.

Curtis, C.E., D'Esposito, M., 2003. Success and failure suppressing reflexive behavior. J. Cognitive Neurosci. 15 (3), 409-418. http://doi.org/10.1162/ 089892903321593126.

Dale, A.M., 1999. Optimal experimental design for event-related fMRI. Hum. Brain Mapp. $8,109-114$

Davis, S.W., Dennis, N.A., Daselaar, S.M., Fleck, M.S., Cabeza, R., 2008. Que PASA? The posterior-anterior shift in aging. Cereb. Cortex 18 (5), 1201-1209. New York, N.Y.: 1991. http://doi.org/10.1093/cercor/bhm155.

DeSouza, J.F.X., Menon, R.S., Everling, S., 2003. Preparatory set associated with prosaccades and anti-saccades in humans investigated with event-related FMRI. J. Neurophysiol. 89 (2), 1016-1023. http://doi.org/10.1152/jn.00562.2002.

Eyler, L.T., Sherzai, A., Kaup, A.R., Jeste, D.V., 2011. A review of functional brain imaging correlates of successful cognitive aging. Biol. Psychiatry 70 (2), 115-122. http://doi. org/10.1016/j.biopsych.2010.12.032.

Fischer, B., Weber, H., 1997. Effects of stimulus conditions on the performance of antisaccades in man. Exp. Brain Res. 116 (2), 191-200. http://doi.org/10.1007/ PL00005749.

Ford, K.A., Goltz, H.C., Brown, M.R.G., Everling, S., 2005. Neural processes associated with antisaccade task performance investigated with event-related FMRI J. Neurophysiol. 94 (1), 429-440. http://doi.org/10.1152/jn.00471.2004.

Ford, K.A., Goltz, H.C., Brown, M.R.G., Everling, S., Kristen, A., 2006. Neural processes associated with antisaccade task performance investigated with event-related fMRI neural processes associated with antisaccade task performance investigated with event-related fMRI. J. Neurophysiol. 94, 429-440. February 2005. http://doi.org/10. 1152/jn.00471.2004.

Guitton, D., Buchtel, H.A., Douglas, R.M., 1985. Frontal lobe lesions in man cause difficulties in suppressing reflexive glances and in generating goal-directed saccades. Exp. Brain Res. 58 (3), 455-472. http://doi.org/10.1007/BF00235863.
Hallett, P.E., 1978. Primary and secondary saccades to goals defined by instructions. Vis. Res. 18 (10), 1279-1296. http://doi.org/10.1016/0042-6989(78)90218-3.

Jamadar, S.D., Fielding, J., Egan, G.F., 2013. Quantitative meta-analysis of fMRI and PET studies reveals consistent activation in fronto-striatal-parietal regions and cerebellum during antisaccades and prosaccades. Front. Psychol. 4, 1-15. OCT. http://doi.org 10.3389/fpsyg.2013.00749.

Johnston, K., Levin, H.M., Koval, M.J., Everling, S., 2007. Top-down control-signal dynamics in anterior cingulate and prefrontal cortex neurons following task switching. Neuron 53 (3), 453-462. http://doi.org/10.1016/j.neuron.2006.12.023.

Koechlin, E., Basso, G., Pietrini, P., Panzer, S., Grafman, J., 1999. The role of the anterior prefrontal cortex in human cognition. Nature 399 (6732), 148-151. http://doi.org/ $10.1038 / 20178$.

Luna, B., Thulborn, K.R., Strojwas, M.H., McCurtain, B.J., Berman, R.A., Genovese, C.R., Sweeney, J.A., 1998. Dorsal cortical regions subserving visually guided saccades in humans: an fMRI study. Cereb. Cortex 8 (1), 40-47. New York, N.Y.: 1991, Retrieved from. http://www.ncbi.nlm.nih.gov/pubmed/9510384.

McDowell, J.E., Brown, G.G., Paulus, M., Martinez, A., Stewart, S.E., Dubowitz, D.J., Braff, D.L., 2002. Neural correlates of refixation saccades and antisaccades in normal and schizophrenia subjects. Biol. Psychiatry 51 (3), 216-223. http://doi.org/10. 1016/S0006-3223(01)01204-5.

McIntosh, A.R., Sekuler, A.B., Penpeci, C., Rajah, M.N., Grady, C.L., Sekuler, R., Bennett, P.J., 1999. Recruitment of unique neural systems to support visual memory in normal aging. Curr. Biol. 9.

Mirsky, J.B., Heuer, H.W., Jafari, A., Kramer, J.H., Schenk, K., Viskontas, I.V., et al., 2013. Anti-saccade performance predicts executive function and brain structure in normal elders. Cognitive Behav. Neurol. 24 (2), 50-58. http://doi.org/10.1097/WNN. ob013e318223f6c6. Anti-saccade.

Morcom, A.M., Johnson, W., 2015. Neural reorganization and compensation in aging. J. Cognitive Neurosci. 27 (7), 1275-1285. http://doi.org/10.1162/jocn_a 00783.

Munoz, D.P., Corneil, B.D., 1995. Evidence for interactions between target selection and visual fixation for saccade generation in humans. Exp. Brain Res. 103 (1), 168-173. http://doi.org/10.1007/BF00241974.

Munoz, D.P., Everling, S., 2004. Look away: the anti-saccade task and the voluntary control of eye movement. Nat. Rev. Neurosci. 5, 218-228. February. http://doi.org/ 10.1038/nrn1345.

Munoz, D.P., Broughton, J.R., Goldring, J.E., Armstrong, I.T., 1998. Age-related performance of human subjects on saccadic eye movement tasks. Exp. Brain Res. 121 (4), 391-400. http://doi.org/10.1007/s002210050473.

Nelles, G., de Greiff, A., Pscherer, A., Esser, J., 2009. Age-related differences of saccade induced cortical activation. Neurosci. Lett. 458 (1), 15-18. http://doi.org/10.1016/j. neulet.2009.04.026.

Nyberg, L., Lövdén, M., Riklund, K., Lindenberger, U., Bäckman, L., 2012. Memory aging and brain maintenance. Trends Cognitive Sci. 16 (5), 292-305. http://doi.org/10. 1016/j.tics.2012.04.005.

Nyffeler, T., Müri, R.M., Bucher-Ottiger, Y., Pierrot-Deseilligny, C., Gaymard, B., RivaudPechoux, S., 2007. Inhibitory control of the human dorsolateral prefrontal cortex during the anti-saccade paradigm - a transcranial magnetic stimulation study. Eur. J. Neurosci. 26 (5), 1381-1385. http://doi.org/10.1111/j.1460-9568.2007.05758.x.

Ogawa, S., Lee, T.M., Kay, A.R., Tank, D.W., 1990. Brain magnetic resonance imaging with contrast dependent on blood oxygenation. Proc. Natl. Acad. Sci. U. S. A. 87 (24), 9868-9872. Retrieved from. http://www.ncbi.nlm.nih.gov/pubmed/2124706.

Olincy, A., Ross, R., Youngd, D., Freedman, R., 1997. Age diminishes performance on an antisaccade eye movement task. Neurobiol. Aging 18 (5), 483-489. http://doi.org/ 10.1016/S0197-4580(97)00109-7.

Pa, J., Dutt, S., Mirsky, J.B., Heuer, H.W., Keselman, P., Kong, E., et al., 2014. The functional oculomotor network and saccadic cognitive control in healthy elders. NeuroImage 95, 61-68. http://doi.org/10.1016/j.neuroimage.2014.03.051.

Park, D.C., Reuter-Lorenz, P., 2009. The adaptive brain: aging and neurocognitive scaffolding. Annu. Rev. Psychol. 60, 173-196. http://doi.org/10.1146/annurev. psych.59.103006.093656.

Peltsch, A., Hemraj, A., Garcia, A., Munoz, D.P., 2011. Age-related trends in saccade characteristics among the elderly. Neurobiol. Aging 32 (4), 669-679. http://doi.org/ 10.1016/j.neurobiolaging.2009.04.001.

Peltsch, A., Hemraj, A., Garcia, A., Munoz, D.P., 2014. Saccade deficits in amnestic mild cognitive impairment resemble mild Alzheimer's disease. Eur. J. Neurosci. 39 (11) 2000-2013. http://doi.org/10.1111/ejn.12617.

Pierrot-Deseilligny, C., Rivaud, S., Gaymard, B., Agid, Y., 1991. Cortical control of reflexive visually-guided saccades. Brain 114 (3).

Pierrot-Deseilligny, C., Müri, R.M., Ploner, C.J., Gaymard, B., Demeret, S., Rivaud Pechoux, S., 2003. Decisional role of the dorsolateral prefrontal cortex in ocular motor behaviour. Brain A J. Neurol. 126 (Pt 6), 1460-1473. http://doi.org/10.1093/ brain/awg148.

Polli, F.E., Barton, J.J.S., Cain, M.S., Thakkar, K.N., Rauch, S.L., Manoach, D.S., 2005. Rostral and dorsal anterior cingulate cortex make dissociable contributions during antisaccade error commission. Proc. Natl. Acad. Sci. U. S. A. 102 (43), 15700-15705. http://doi.org/10.1073/pnas.0503657102.

Rabbitt, P., 1965. An age decrement in the ability to ignore irrelevant information. J. Gerontol. 20 (2), 233-238. http://doi.org/10.1093/geronj/20.2.233.

Raemaekers, M., Vink, M., van den Heuvel, M.P., Kahn, R.S., Ramsey, N.F., 2006. Effects of aging on BOLD fMRI during prosaccades and antisaccades. J. Cognitive Neurosci. 18 (4), 594-603. http://doi.org/10.1162/jocn.2006.18.4.594.

Rapp, P.R., Amaral, D.G., 1992. Individual differences in the cognitive and neurobiological consequences of normal aging. Trends Neurosci. 15 (9), 340-345. http://doi.org/10.1016/0166-2236(92)90051-9. 
Reuter-Lorenz, P.A., Cappell, K.A., 2008. Neurocognitive aging and the compensation hypothesis. Curr. Dir. Psychol. Sci. 17 (3), 177-182. http://doi.org/10.1111/j.1467 8721.2008.00570.x.

Rossi, S., Miniussi, C., Pasqualetti, P., Babiloni, C., Rossini, P.M., Cappa, S.F., 2004. Agerelated functional changes of prefrontal cortex in long-term memory: a repetitive transcranial magnetic stimulation study. J. Neurosci. 24 (36), 7939-7944. http://doi. org/10.1523/JNEUROSCI.0703-04.2004.

Salthouse, T.A., 2010. Selective review of cognitive aging. J. Int. Neuropsychol. Soc. JINS 16 (5), 754-760. http://doi.org/10.1017/S1355617710000706.

Schneider-Garces, N.J., Gordon, B.A., Brumback-Peltz, C.R., Shin, E., Lee, Y., Sutton, B.P., et al., 2010. Span, CRUNCH, and beyond: working memory capacity and the aging brain. J. Cognitive Neurosci. 22 (4), 655-669. http://doi.org/10.1162/jocn.2009. 21230.

Hakvoort Schwerdtfeger, R.M., Alahyane, N., Brien, D.C., Coe, B.C., Stroman, P.W., Munoz, D.P., 2013. Preparatory neural networks are impaired in adults with attention-deficit/hyperactivity disorder during the antisaccade task. NeuroImage Clin. 2 (1), 63-78. http://doi.org/10.1016/j.nicl.2012.10.006.

Spreng, R.N., Wojtowicz, M., Grady, C.L., 2010. Reliable differences in brain activity between young and old adults: a quantitative meta-analysis across multiple cognitive domains. Neurosci. Biobehav. Rev. 34 (8), 1178-1194. http://doi.org/10.1016/j. neubiorev.2010.01.009.

Talairach, J., Tournoux, P., 1988. Stereotaxic Atlas of the Human Brain. Thieme New York, first ed., vol. 270. Thieme Medical Publishers, New York. Retrieved from. http://scholar.google.pl/scholar?hl=pl\&as_

$\mathrm{sdt}=0,5 \& \mathrm{q}=$ Talairach + and + Tournoux $+1988+$ stuttgart $\# 4$.

Watanabe, M., Munoz, D.P., 2011. Probing basal ganglia functions by saccade eye movements. Eur. J. Neurosci. 33 (11), 2070-2090. http://doi.org/10.1111/j.1460 9568.2011.07691.x.

Witiuk, K., Fernandez-Ruiz, J., McKee, R., Alahyane, N., Coe, B.C., Melanson, M., Munoz, D.P., 2014. Cognitive deterioration and functional compensation in ALS measured with fMRI using an inhibitory task. J. Neurosci. Off. J. Soc. Neurosci. 34 (43), 14260-14271. http://doi.org/10.1523/JNEUROSCI.1111-14.2014.

World Medical Association, W.M., 2001. World Medical Association Declaration of Helsinki. Ethical principles for medical research involving human subjects. Bull. World Health Organ. 79 (4), 373-374. Retrieved from. http://www.ncbi.nlm.nih. gov/pubmed/11357217.

Yang, Q., Kapoula, Z., 2006. The control of vertical saccades in aged subjects. Exp. Brain Res. 171 (1), 67-77. http://doi.org/10.1007/s00221-005-0249-x. 